\title{
Cholesterol level determines viability and mitogenicity, but it does not affect sodium butyrate-dependent sensitization of Colo 205 cells to TNF- $\alpha$-induced apoptosis
}

\author{
S. ORZECHOWSKA ${ }^{1}$, B. PAJAK ${ }^{1}$, B. GAJKOWSKA ${ }^{1}$ and A. ORZECHOWSKI ${ }^{1,2}$ \\ ${ }^{1}$ Department of Cell Ultrastructure, Mossakowski Medical Research Centre, Polish Academy of Sciences, \\ Pawinskiego 5, 02-106 Warsaw; ${ }^{2}$ Department of Physiological Sciences, Faculty of Veterinary Medicine, \\ Warsaw University of Life Sciences (SGGW), Nowoursynowska 159, 02-776 Warsaw, Poland
}

Received September 24, 2010; Accepted November 5, 2010

DOI: 10.3892/or.2010.1081

\begin{abstract}
Transient treatment of human adenocarcinoma COLO 205 cells with lipit raft (LR) modulators (MBCD, NY, IMP) was followed by the challenge with metabolic inhibitors and selected anti-cancer drugs. To overturn cholesterol chelation, the MBCD, NY treatment was followed by cholesterol conjugates (CHOL-MßCD or CHOL-PEG). The TNF- $\alpha$ - and P(Ser473)-PKB/Akt1/2-mediated effects initiated at LR were evaluated with regard to cell viability and mitogenicity. Cholesterol chelators reversibly reduced cell survival, whereas some of the tested compounds had weak effects (CIS, CLA), stimulated (EGCG) or reduced $(\mathrm{NaB})$ cell survival. Cellular localizations of LR-associated molecules (ceramides, $\mathrm{G}_{\mathrm{\alpha i}-2}$ heterotrimeric protein, and TNFR1) in different cellular compartments including the plasma membrane were observed in the respective photographs from TEM and SEM. Evidence from SEM also showed that TNF-R1 is clustered on the surface of COLO 205 cells without presence of cognate ligand but clustering is promoted by TNF- $\alpha$, while it vanished after IMP treatment. COLO 205 cells remained immune to TNF- $\alpha$-induced apoptosis unless $\mathrm{NaB}$ was added, in which case $\mathrm{NaB}$-induced cell death was further potentiated by TNF- $\alpha$. Combined $\mathrm{NaB}$ and TNF- $\alpha$ treatment was associated with marked changes in the expression of pro- and antiapoptotic proteins. In this study, we demonstrated that initial excess of prosurvival signals could be diminished by cholesterol chelators, whereas LR-independent cell survival could be targeted by $\mathrm{NaB}$. Apparently, lipid rafts do not participate in NaB-dependent cell death.
\end{abstract}

Correspondence to: Dr A. Orzechowski, Department of Cell Ultrastructure, Mossakowski Medical Research Centre, Polish Academy of Sciences, Pawinskiego 5, 02-106 Warsaw, Poland E-mail: orzechowski_arkadiusz@wp.pl

Key words: lipid rafts, cholesterol, Akt1/2, TNF- $\alpha$, COLO 205 cells, viability, mitogenicity, apoptosis

\section{Introduction}

The idea of lipid rafts (LR) over the years remained elusive and tricky to observe. Recent progress in experimental technologies such as fluorescence resonance energy transfer (FRET), fluorescence recovery after bleaching (FRAP), and finally fluorescence correlation spectroscopy (1) provided evidence that rafts are extremely small (5-20 $\mathrm{nm}$ in diameter), highly dynamic, and involve interactions of both proteins and lipids (2). They are thought to be plasma membrane lateral assemblies enriched in cholesterol and sphingomyelin (SPHING) which associate together, away from the more abundant unsaturated phospholipids (3). Some proteins prefer LR (glycosylphosphatidylinositol, GPIanchored) while others (EGF receptors, EGF-R) do not (4). This led to the hypothesis that LR are basic platforms to organize signaling proteins. Actually, among others $B$ secretase, flotillin or $\mathrm{G}_{\mathrm{ai}-2}$ are constitutively expressed in raft nanodomains being routine markers of LR, while other proteins, i.e. TNF-R1 or PKB/Akt1/2 interact temporarily with LR (1). LR facilitate recruitment and activation of $\mathrm{PKB} /$ Akt1/2, upon phosphatidylinositol-3-kinase (PI3-K)-dependent phosphatidylinositol-3,4,5-triphosphate modification. Similarly, TNF-R1 receptor may oligomerize in response to ceramides freed from sphingomyelin by sphingomyelinases (SMA-ses) (5).

In the extensive search for the platform which segregates pro- and antiapoptotic signals, lipid rafts seem to be the most likely site for consideration. First, when the LR became the focus of attention $(4,6)$ it became clear that both death and survival signals elicited by respective cytokines have to originate from these small entities (7). Of course, other than LR portion of plasma membrane also contributes to cell fate. In any case, LR are the only known nanodomains where the transmembrane proteins may interact through the raft clustering $(8,9)$. In the initiation of signaling cascades it is essential for the receptors to assemble into polymers (dimers, trimers). For survival, the most prominent cascade is PI3K/Akt1/2/GSK-3ß while cell death could be regularly evoked by TNF- $\alpha$ /TNF-R1/TRADD and other death ligands (FasL, TRAIL). Either system is frequently disturbed in tumor cells, 
where the first is often up- and the latter is down-regulated (gain and/or loss of function). This is the case for COLO 205 cells, the cell line particularly hard for deletion and therefore suitable model for this study. Upon alteration of raft composition we examined two critically important signaling pathways, namely PI3-K/Akt1/2/GSK-3ß and TNF- $\alpha$ / TNFR1/TRADD in COLO 205 cells. Several factors (metabolic inhibitors, anti-cancer drugs) have been tested in order to find out whether they act through LR and how they affect the above-mentioned signaling cascades. To provide evidence at ultrastructural level, scanning (SEM) and transmission (TEM) electron microscopy were used.

\section{Materials and methods}

All reagents were cell culture tested, of high purity and unless otherwise stated they were purchased from Sigma-Aldrich Chemical Co. (St. Louis, MO, USA). Plastics were from Corning-Costar Inc. (Cambridge, MA, USA), while sera (heat-inactivated), media, PBS and antibiotics were from Gibco Life Technologies (Grand Island, NY, USA). The cholesterol-methyl-ß-cyclodextrin (CHOL-MßCD) inclusion complex was prepared as described by Klein et al (10) and Gimple et al (11). Briefly, $300 \mathrm{mg}$ of cholesterol was dissolved in 2-propanol and was added to a stirred solution of methylB-cyclodextrin (MBCD, $5 \% \mathrm{w} / \mathrm{v})$ on a water bath $\left(80^{\circ} \mathrm{C}\right)$. The mixture was stirred at $80^{\circ} \mathrm{C}$ until the initially precipitating steroid was completely dissolved. The solution was freezedried and stored at room temperature for use at concentration of $100 \mu 1 / 15 \mathrm{ml}$ of medium. Also ready to use polyethylenglycol conjugated to cholesterol (CHOL-PEG, $100 \mu \mathrm{g} / \mathrm{ml}$ ) was applied to run LR up with cholesterol.

Human colon adenocarcinoma cell line COLO 205 was purchased from American Type Culture Collection (ATCC, Manassas, VA, USA). Cells were maintained in exponential phase of growth in growth medium [GM, $100 \mathrm{ml} / 1$ fetal bovine serum (FBS)/Dulbecco's modified Eagle medium (DMEM) with Glutamax and antibiotic-antimycotic mixture]. The cells were grown at $37^{\circ} \mathrm{C}$, in a controlled, humidified $50 \mathrm{ml} / \mathrm{C} \mathrm{CO}_{2}$ atmosphere, on a multiwell (96) or tissue culture Petri dishes (100-mm diameter, BD Biosciences, Franklin Lakes, NJ, USA). During propagation, medium was changed every other day until cultures reached $80 \%$ confluence. One day $(24 \mathrm{~h})$ prior to the experiment, confluent cells were withdrawn from cell cycle by replacing GM with $20 \mathrm{~g} / 1 \mathrm{BSA} / \mathrm{DMEM}$ designated as control medium (CTRL). During the study freshly prepared media with or without experimental factors were used, whereas vehicle $(0.1 \%$ DMSO) was added to the control system. Exactly $30 \mathrm{~min}$ prior to the application of water-soluble reagents, DMSO-dissolved reagents (cycloheximide, CHX; actinomycin D,- AD; PD098059 or LY294002) were applied.

Cell viability/proliferation was based on the ability of cells grown on multiplate wells to convert soluble MTT (3-(4,5dimethylthiazol-2-yl)-2-5-diphenyltetrazolium bromide) into an insoluble purple formazan reaction product with minor modifications to protocol described by Jacobson et al (12).

Cell mitogenicity was determined by crystal violet $(\mathrm{CV})$ assay on 96-multiwell plates. Upon completing the experiment cells were washed with PBS and fixed with two-step bath in ice-cold methanol (70\% followed by $100 \%$, v/v, $20 \mathrm{~min}$, $4^{\circ} \mathrm{C}$ ). Next, cells were immersed in $0.2 \%$, w/v crystal violet solution in dd $\mathrm{H}_{2} \mathrm{O}$ with ethanol $2 \%$, v/v for $10 \mathrm{~min}$. Subsequently, they were gently washed with dd. $\mathrm{H}_{2} \mathrm{O}$, air dried and incubated with SDS solution $\left(1 \%, \mathrm{w} / \mathrm{v}\right.$ in dd. $\left.\mathrm{H}_{2} \mathrm{O}\right)$. The absorbances for MTT and CV were measured at $570 \mathrm{~nm}$ with ELISA reader type Infinite 200 (Tecan, Austria). Percentage of viable or proliferating cells was measured by MTT conversion into purple formazan and quantity of $\mathrm{CV}$ bound to cellular DNA, respectively.

Rafts were isolated by extraction with Brij 98 at $37^{\circ} \mathrm{C}$, as previously reported by Drevot et al (13) with modification of Remacle-Bonnet et al (14). In brief, cells were harvested with a rubber policeman and gently sonicated (five 5-sec bursts, $5 \mathrm{~W}$ ) in $1 \mathrm{ml}$ of ice-cold buffer A (25 mmol/l HEPES, $150 \mathrm{mmol} / \mathrm{l} \mathrm{NaCl}, 1 \mathrm{mmol} / \mathrm{l}$ EGTA, $10 \mathrm{mmol} / \mathrm{l} \mathrm{NaF}, 5 \mathrm{mmol} / \mathrm{l}$ $\mathrm{Na}_{3} \mathrm{VO}_{4}, 10 \mathrm{mmol} / 1 \mathrm{NaP}-\mathrm{P}$, and a mixture of protease inhibitors). The postnuclear supernatant was recovered after centrifugation at $800 \mathrm{x} \mathrm{g}$ at $4^{\circ} \mathrm{C}$ for $10 \mathrm{~min}$, and then spun at $100,000 \mathrm{x} \mathrm{g}$ in a SW41 rotor (Beckman Instruments) for $60 \mathrm{~min}$ at $4^{\circ} \mathrm{C}$ and the supernatant was referred as the soluble fraction (S) containing solubilized membrane and cytosolic fractions. The membrane raft fraction in the pellet (R) was resuspended in buffer A containing 1\% Brij 98, 0.3\% deoxycholic acid, and $60 \mathrm{mmol} / \mathrm{l} n$-octyl- $\beta$-D-glucopyranoside (ODG), and nonsoluble material was removed by an additional centrifugation. Collected (S) and (R) fraction from an identical number of cells were analyzed by WB. Finally, for protein quantification, blots were scanned and analyzed by spot densitometry, and results were expressed as average value of pixels enclosed (AVG), calculated as the sum of all the pixel values after background correction divided by area.

In turn, for whole-cell lysates, the cells were cultured with or without experimental factors indicated in figure legends, harvested, washed, and lysed with RIPA lysis buffer (1X PBS, $10 \mathrm{ml} / 1$ Igepal CA-630, $5 \mathrm{~g} / 1$ sodium deoxycholate, $1 \mathrm{~g} / \mathrm{l} \mathrm{SDS}$ ) supplemented with $0.4 \mathrm{mM} \mathrm{PMSF}, 10 \mu \mathrm{g} / \mathrm{ml}$ of aprotinin and $10 \mu \mathrm{g} / \mathrm{ml}$ of sodium orthovanadate was added. To lyse the cell pellet, cells were broken up by repetitive triturating with the syringe with attached needle ( $21 \mathrm{G}, 0.8$-mm diameter). Cell suspension was then left on ice $\left(4^{\circ} \mathrm{C}\right)$ for $30 \mathrm{~min}$, and centrifuged for another $5 \min \left(4^{\circ} \mathrm{C}, 10,000 \mathrm{x} \mathrm{g}\right)$. Next, viscous solution was divided into smaller volumes and transferred to fresh Eppendorf tubes and stored at $-80^{\circ} \mathrm{C}$ until used. For protein quantification in the whole-cell lysates the proteindye-binding method by Bradford (15) with commercial reagent was used (Bio-Rad Laboratories, Hercules, CA, USA).

Cell lysates (equal protein loads) were subjected to SDSPAGE, transferred to polyvinylidene difluoride membrane, and immunoblotted with antibodies against phosphorylated and/or non-phosphorylated forms of proteins: actin, $\mathrm{PKB} / \mathrm{Akt}-1 / 2$ and P(Ser473)-PKB/Akt1/2, Bax, Bcl-2, Bid, caspase-3/procaspase-3, cIAP-1, ERK1/2 and P(Y204)ERK1/2, GSK-3ß and P(Ser9)-GSK-3ß, G $\mathrm{ai}-2_{2}$, survivin, TRADD (Santa Cruz Biotechnology, Santa Cruz, CA, USA). Secondary polyclonal antibodies (Santa Cruz Biotechnology) raised against respective species and conjugated to horseradish peroxidase were used for detection, followed by enhanced chemiluminescence assay (Amersham International, 

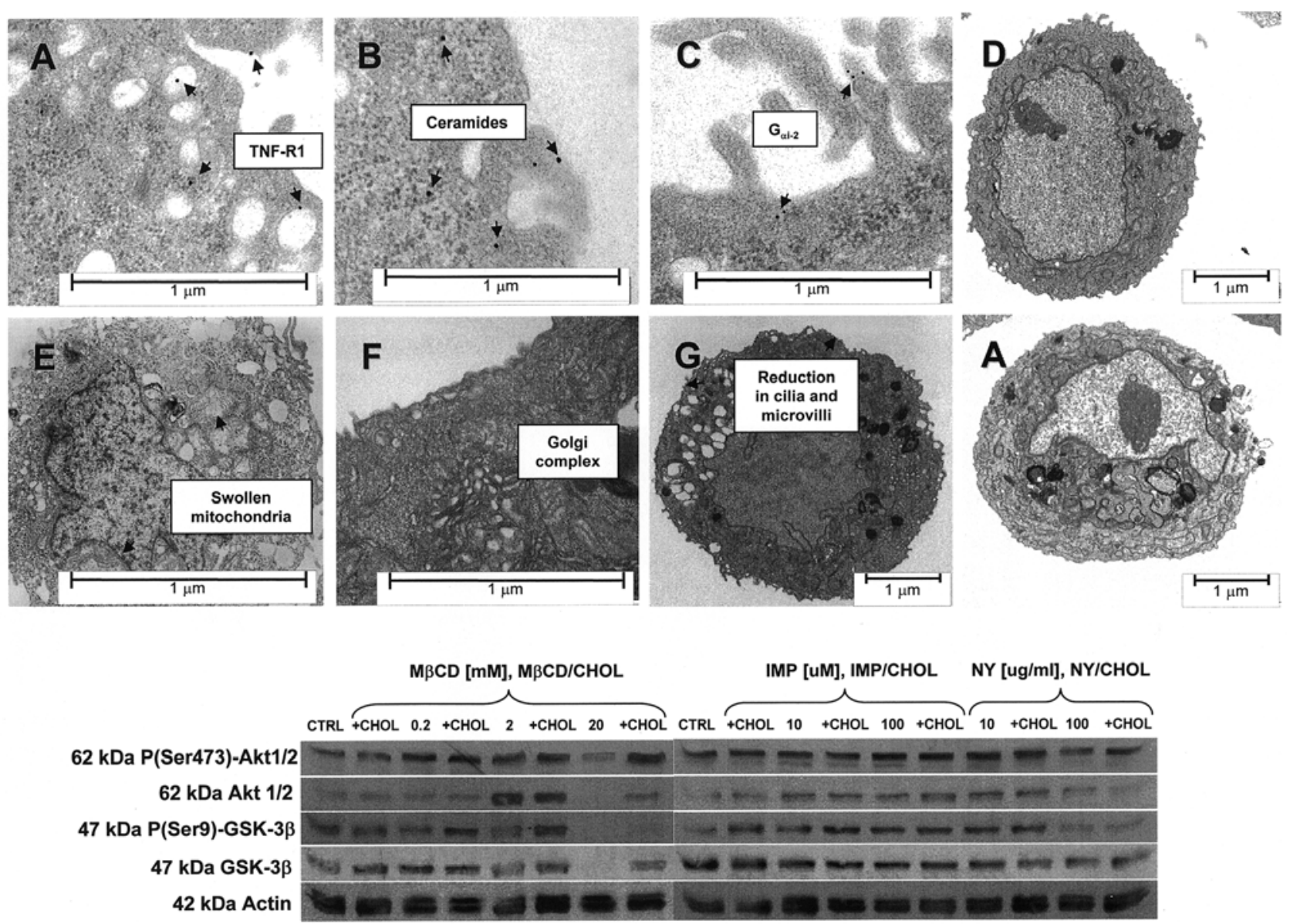

Figure 1. Top: Series of ultrastructural views of control (upper panel) and treated (lower panel) COLO 205 cells. Upper panel: immunocytochemical detection of TNF-R1, ceramides, and $\mathrm{G}_{\mathrm{ai}-2}$ protein (TNF-R1 $18 \mathrm{~nm}$, cermide $18 \mathrm{~nm}, \mathrm{G}_{\mathrm{ai}-2} 12 \mathrm{~nm}$ diameter, respectively). Lower panel: morphological appearances of COLO 205 cells treated for $1 \mathrm{~h}$ with $2 \mathrm{mM}$ of MBCD followed by replenishment of cholesterol with $1 \mathrm{~h} \mathrm{CHOL-MBCD}(100 \mu 1 / 15 \mathrm{ml}$, see Materials and methods). Bottom: Immunoblots from whole-cell lysates obtained from COLO 205 cells treated for $1 \mathrm{~h}$ with increasing concentrations of MBCD, 0.2, 2, 20 mM; IMP, $10,100 \mu \mathrm{M}$; or NY, 10, $100 \mu \mathrm{g} / \mathrm{ml}$. Afterwards, cells were recovered for $1 \mathrm{~h}$ by the addition of CHOL-PEG (100 $\mu \mathrm{g} / \mathrm{ml}$, see Material and methods). To demonstrate activity of survival system (PI3-K/Akt1/2) the expression levels of PKB/Akt1/2, P(Ser473)-PKB/ Akt1/2, GSK-3B, P(Ser9)-GSK-3ß are shown.

Aylesbury, UK). After exposure, and processing the film was scanned and analyzed using Kodak EDAS 290/Kodak 1D 3.5 system.

Post-embedment immunostaining was performed on $4 \%$ paraformaldehyde: $0.1 \%$ glutaraldehyde fixed cells with antibodies raised against $\mathrm{G}_{\mathrm{ai}-2}$ or/and TNF-R1 or/and ceramide (Santa Cruz Biotechnology). Ultrathin sections were mounted on the formvar-coated nickel grids, air-dried and stained for 10 min with $4.7 \%$ uranyl acetate and for 2 min with lead citrate. Secondary antibodies conjugated with colloidal gold particles (Jackson Immunoresearch, West Grove, PA, USA) were used to demonstrate immunoreactivity of investigated proteins (TNF-R1 $18 \mathrm{~nm}$, cermide $18 \mathrm{~nm}, \mathrm{G}_{\mathrm{\alpha i}-2} 12 \mathrm{~nm}$ diameter, respectively). The sections were examined and photographed with JEOL 1011XE electron microscope (Jeol, Tokyo, Japan).

The QuantomiX QX-102 system (QuantomiX Ltd. Rehovot, Israel) was applied to show the presence and distribution of TNF- $\alpha$ receptors (TNF-R1) on plasma membranes of wet COLO 205 cells after fixation (2\% paraformaldehyde and $0.1 \%$ glutaraldehyde solution in PBS) and two-step immunodetection with colloidal gold particles (Jackson Immunoresearch). Gold particles (18 $\mathrm{nm}$ in diameter) were demonstrated and photographed with JEOL JSM3690LV scanning electron microscope (Jeol).
Statistical evaluation. Each experiment was repeated at least twice with identical results. The data are expressed as the means \pm SE. Statistical significance was determined using one-way ANOVA for multiple comparisons followed by the Tukey multiple range test. $\mathrm{P}<0.05$ was con-sidered significant. In the figures statistical differences from control values are indicated by asterisks $\left({ }^{*} \mathrm{P}<0.05 ;{ }^{* *} \mathrm{P}<0.01\right.$; ${ }^{* * *} \mathrm{P}<0.001$ ), whereas statistical differences between the means are ticked with different lower case letters. These analyses were performed using GraphPad Prism ${ }^{\text {TM }}$ version 4.03 software (GraphPad Software Inc., San Diego, CA, USA).

\section{Results}

Short-term deprivation of plasma membrane cholesterol impairs cell survival, although it is not lethal to COLO 205 cells if followed by cholesterol replenishment. To evaluate the input of LR to the effects of examined substances, first we tested how the LR modulators impinge on the level phosphorylated (active) form of PKB/Akt1/2 known to be specific indicator of intact LR (1) and viable cells. Methyl- $\beta$ cyclo-dextrin (MBCD) and nystatin (NY) were tested at different concentrations $(0.2,2,20 \mathrm{mM})$ for $\mathrm{MBCD}$ and $(10$, $100 \mu \mathrm{g} / \mathrm{ml}$ ) for NY. Additionally, imipramine (IMP) was used 
A

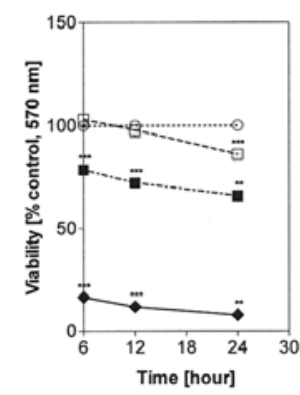

Dose-response curves for LR modulators
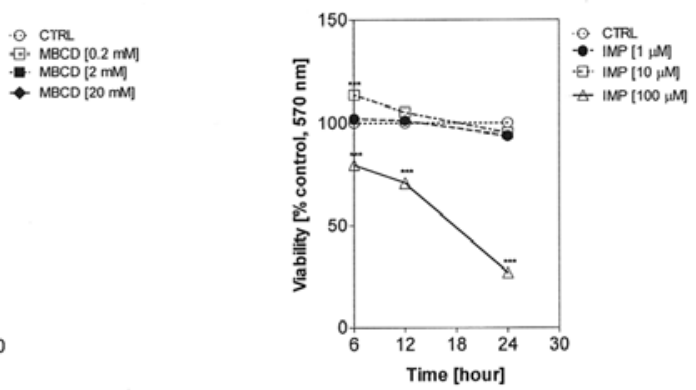

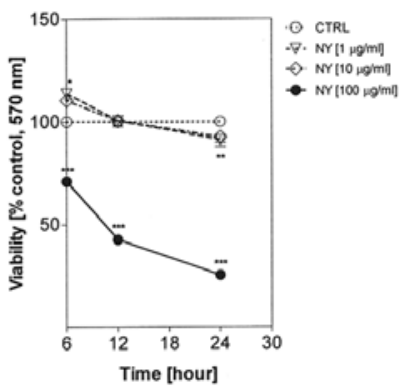

B

Dose-response curves for TNF- $\alpha, \mathrm{NaB}$ and IMP
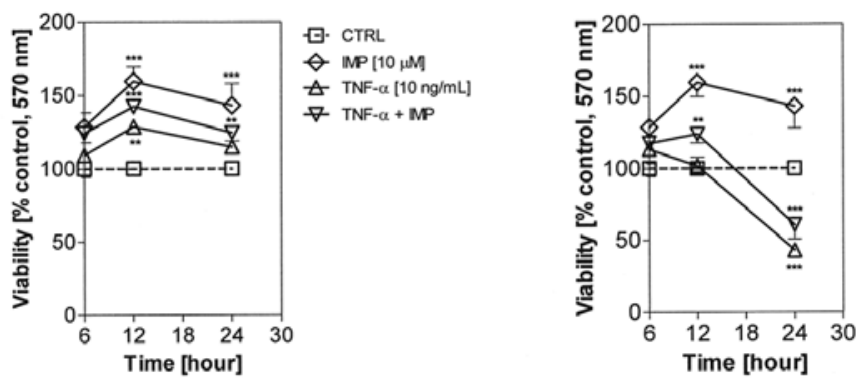

ㅁ. CTRL.

$\diamond \mathrm{IMP}[10 \mu \mathrm{M}]$

$\nabla \mathrm{NaB}+\mathrm{IMP}$

$\triangle$ TNF- $\alpha[10 \mathrm{ng} / \mathrm{mL}$

$\nabla \mathrm{TNF}-\alpha+\mathrm{MP}$

Time [hour]

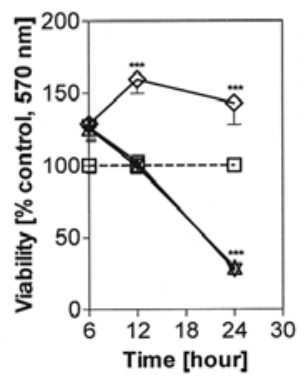

口. CTRL

$\vartheta$ IMP $[10 \mu \mathrm{M}]$

$\forall \mathrm{NaB}+\mathrm{TNF}-\alpha$

$\triangle \mathrm{NaB}+\mathrm{TNF}-\alpha+$ IMP

C

Dose-response curves for anti-cancer drugs
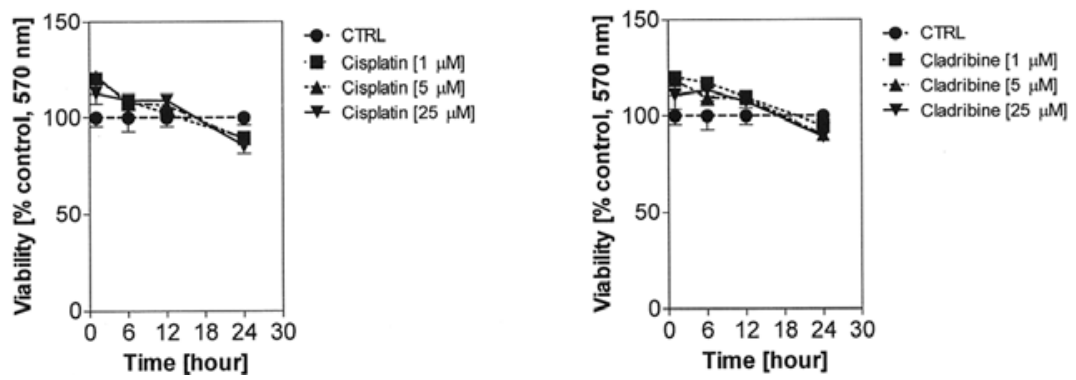

Figure 2. (A) The dose-response effect of each LR modulator on cell viability is shown. Highest concentrations used (20 mM of MßCD, $100 \mu \mathrm{g} / \mathrm{ml}$ of NY and $100 \mu \mathrm{M}$ of IMP) were apparently cytotoxic. Moderate concentrations were chosen for further experiments. (B) The dose response-curves representing cell viability upon treatment with TNF- $\alpha$ and/or NaB and/or not IMP. IMP stimulated cell viability, also it reduced the cytotoxicity of NaB and elevated response to TNF- $\alpha$. No effect of IMP was observed when both TNF- $\alpha$ and NaB were used together. (C) Anti-cancer drugs (cisplatin, cladribine) were used at increasing concentrations $(1,5,25 \mu \mathrm{M})$ in order to determine if they reduce the metabolic activity of COLO 205 cells. It is clear from the presented curves, that none impaired the metabolic activity of COLO 205 cells. Asterisks indicate values statistically different from the control group $(\mathrm{P}<0.05)$.

$(10,100 \mu \mathrm{M})$ in order to inhibit acidic sphingomyelinase (aSMAse) (16). According to Remacle-Bonnet et al (14) cells might substantially be out of cholesterol (CHOL) upon $1 \mathrm{~h}$ administration with MßCD, but they do not die if they are subsequently washed and/or additionally re-loaded with CHOL. Cells might become briefly detached from substratum ( $2 \mathrm{mM} \mathrm{MBCD}, 1 \mathrm{~h})$, though subsequent recovery make them functional at a molecular and ultrastructural level (Fig. 1). Similar effect was demonstrated for NY $(100 \mu \mathrm{g} / \mathrm{ml}$, data not shown). The $2 \mathrm{mM}$ concentration of MßCD was selected for the subsequent study.

Cell viability is altered by LR modulators and to some extent by metabolic inhibitors. To determine cytotoxic effect of either factor they were initially tested in a dose- and time-dependent manner $(0,1,6,12,24 \mathrm{~h})$. In this study, each LR modulator was apparently cytotoxic after $6 \mathrm{~h}$ at concentrations of 2 and $20 \mathrm{mM}, 100 \mu \mathrm{g} / \mathrm{ml}$ and $100 \mu \mathrm{M}$, for MBCD, NY and IMP, respectively (Fig. $2 \mathrm{~A}, \mathrm{P}<0.05$ ). After $24 \mathrm{~h}$ of incubation the viability was reduced by $92.30 \pm 0.18 \%$ for $20 \mathrm{mM}$ of $\mathrm{MBCD}$, by $74.75 \pm 1.09 \%$ for $100 \mu \mathrm{g} / \mathrm{ml}$ of $\mathrm{NY}$, and by $73.05 \pm 1.31 \%$ for $100 \mu \mathrm{M}$ of IMP (Fig. 2A, P<0.001). The high concentrations of $\mathrm{MBCD}, \mathrm{NY}$ and IMP were selected solely for acute experiments, whereas medium or low range concentrations were helpful to examine transient or chronic effects of LR modulators. Other metabolic inhibitors were tested accordingly. IMP $(10 \mu \mathrm{M})$ stimulated cell survival, and it enhanced viability at the presence of TNF- $\alpha$ or $\mathrm{NaB}$ (Fig. $2 \mathrm{~B}, \mathrm{P}<0.001$ ). IMP did not reduce the effect of both factors used concomitantly. Anti-cancer drugs (CIS and CLA) did not influence significantly viability of COLO 205 cells when added in therapeutic concentrations (1,5 and $25 \mu \mathrm{M}$, Fig. 2C, $\mathrm{P}>0.05$ ), however they moderately decreased cell survival in higher (toxic) concentrations $(50,100,200 \mu \mathrm{M})$, particularly after $24 \mathrm{~h}$ of treatment (data not shown). On the contrary, EGCG did stimulate cell viability (Fig. $3 \mathrm{~A}, \mathrm{P}<0.001$ for 
A

The effect of preincubation with LR modulators (1 h) on EGCG or EGCG + TNF- $\alpha$ treatment
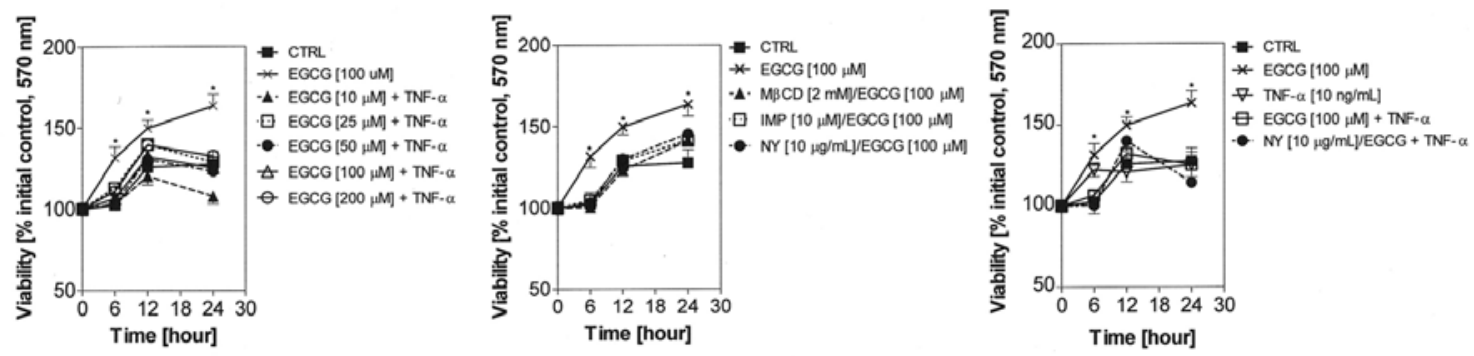

B

The effect of preincubation with $M \beta C D(1 \mathrm{~h})$
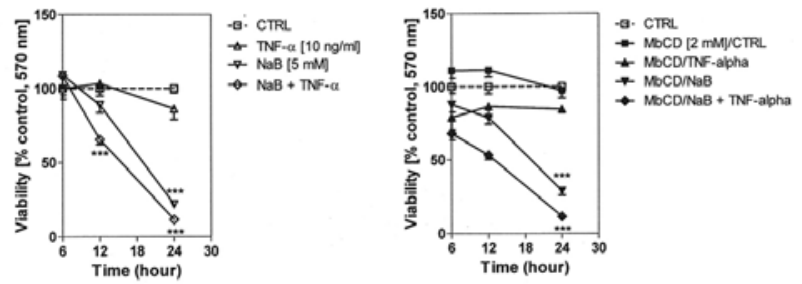

C

The effect of preincubation with M $M C D(1 \mathrm{~h})$

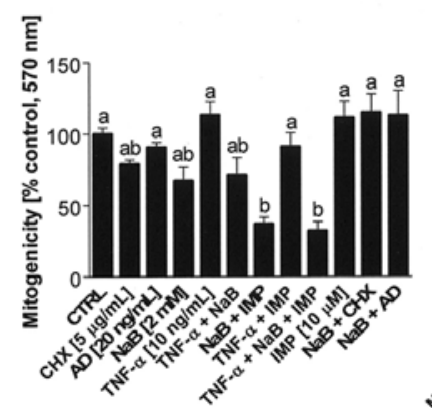

Figure 3. (A) Preincubation (1 h) with MBCD or NY or co-treatment with TNF- $\alpha$ both obstruct the effect of EGCG on viability/proliferation of COLO 205 cells. (B) Preincubation ( $1 \mathrm{~h}$ ) with MßCD reduces the effect of TNF- $\alpha$ but does not affect the cytotoxicity of NaB and TNF- $\alpha$. (C) Mitogenicity of COLO 205 cells is significantly retarded by $\mathrm{NaB}$, regardless of IMP. Preincubation $(1 \mathrm{~h})$ with MBCD does not markedly affect the mitogenic responses to tested substances. Asterisks indicate values statistically different from the control group $(\mathrm{P}<0.05)$.

$100 \mu \mathrm{M})$. Neither of the tested metabolic inhibitors (PD098059 at $50 \mu \mathrm{M}, \mathrm{LY} 294002$ at $50 \mu \mathrm{M}$, and $\mathrm{AD}$ at $20 \mathrm{ng} / \mathrm{ml})$ affected cell survival by $24 \mathrm{~h}$ of experimental period as previously shown by Pajak et al (17). In contrast, profound and timedependent cytotoxic effect was observed after $\mathrm{NaB}$ administration at this same time (Fig. 3C, P<0.001).

LR modulators sensitizeldesensitize cellular responses to certain metabolic inhibitors. Previously, we reported that sodium butyrate $(\mathrm{NaB})$ administered at physiological concentrations (2-5 mM) provoked apoptosis in COLO 205 cells (17). Additionally, when TNF- $\alpha$ was combined with $\mathrm{NaB}$ the latter facilitated TNF- $\alpha$-mediated extrinsic apoptosis. In this study, we verified the involvement of LR in either effect, as well as other factors used by us. Close view did not show any effect of transient CHOL deprivation with MBCD (2 mM) on the NaB-dependent cell death and mitogenic response (Fig. 3B and $\mathrm{C}, \mathrm{P}>0.05)$. In contrast, when $\mathrm{NaB}$ was added together with TNF- $\alpha$, they both acted jointly to delete cells (Figs. 2B, $3 \mathrm{~B}$ and $3 \mathrm{C}, \mathrm{P}<0.001)$. Cytotoxic effect of $\mathrm{NaB}$ could be impeded by co-treatment with $\mathrm{CHX}$ and to some extent with AD, known inhibitors of translation and transcription, respectively (Fig. $4 \mathrm{~A}$ and $\mathrm{B}, \mathrm{P}<0.001$ ). These observations prompted us to examine the expression levels of pro- and antiapoptotic proteins (see below). On the contrary, MBCD $(2 \mathrm{mM})$ and NY $(100 \mu \mathrm{g} / \mathrm{ml})$, the IMP at $10 \mu \mathrm{M}$ was shown to stimulate viability of COLO 205 cells. IMP affected
TNF- $\alpha$ - but not NaB-dependent effect on DNA synthesis (Figs. 2B and 3C, $\mathrm{P}<0.001$ ). Cholesterol deprivation with $\mathrm{M} B C D$ did not affect the cytotoxic outcome of common treatment with TNF- $\alpha$ and $\mathrm{NaB}$ (Fig. 3B, P>0.05) although it markedly reduced the effect of IMP on TNF- $\alpha$-dependent mitogenicity (Fig. 3C, $\mathrm{P}<0.05$ ).

Immunoreactivity of $P K B / A k t 1 / 2$ and its substrate $G S K-3 \beta$ are affected by LR modulators. To set it off, the LR modulators were used in non-toxic concentrations. None of them (MBCD at $0.2 \mathrm{mM}, \mathrm{NY}$ at $10 \mu \mathrm{g} / \mathrm{ml}$ or IMP at $10 \mu \mathrm{M})$ affected the levels of certain immunoreactive proteins determined in wholecell lysates after the short-term $(1 \mathrm{~h})$ treatment (Fig. 5A, $\mathrm{P}>0.05)$. Correspondingly, neither EGCG $(100 \mu \mathrm{M})$, nor TNF- $\alpha(10 \mathrm{ng} / \mathrm{ml})$, nor PD098059 $(50 \mu \mathrm{M})$, nor LR modulators in low concentrations $(0.2 \mathrm{mM}, 10 \mathrm{ng} / \mathrm{ml}$ or $10 \mu \mathrm{M}$ for $\mathrm{MBCD}, \mathrm{NY}$ and IMP, respectively) brought any effect on Akt1/2, P(Ser473)-Akt1/2 and its substrate P(Ser9)-GSK-3ß (data not shown). On the contrary, when MBCD or NY were used in the concentrations of $2 \mathrm{mM}$ and $100 \mu \mathrm{g} / \mathrm{ml}$, respectively, they reduced the levels of $\mathrm{P}(\mathrm{Ser} 473)-\mathrm{PKB} /$ Akt1/2 and $\mathrm{P}($ Ser9)-GSK-3ß (Fig. 1B, $\mathrm{P}<0.05$ ). These effects were fully reversible after cholesterol refill (Figs. $1 \mathrm{~B}$ and $5 \mathrm{~B}$ ). Finally, when the lipid membrane fractions (non-raft, detergent soluble - S, and lipid raft, detergent resistant - R) were isolated, separated and proteins were immunoblotted, the levels of $\mathrm{PKB} / \mathrm{Akt} 1 / 2$ phosphorylated at Ser473 were markedly 
A

\section{The effect of preincubation with $M \beta C D(1 \mathrm{~h})$}
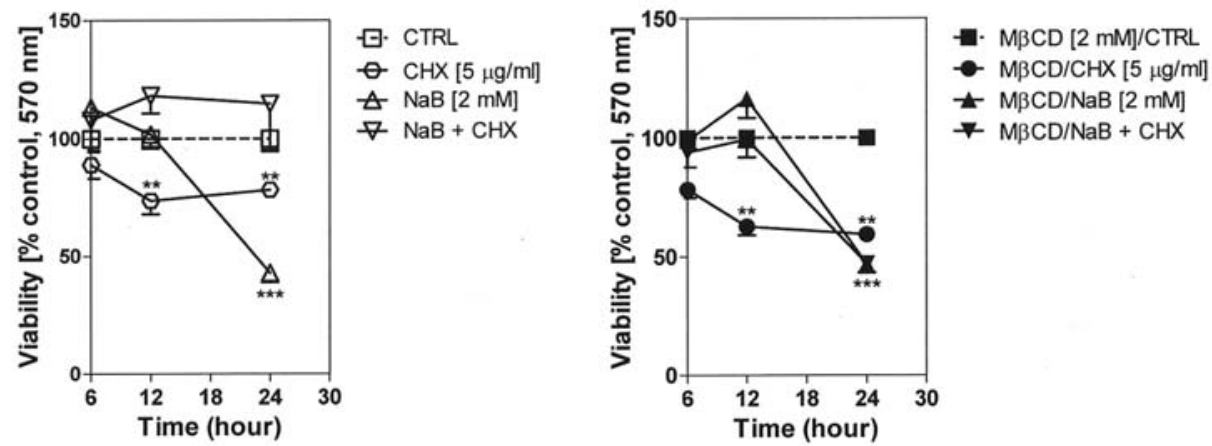

B

The effect of preincubation with $M \beta C D(1 \mathrm{~h})$
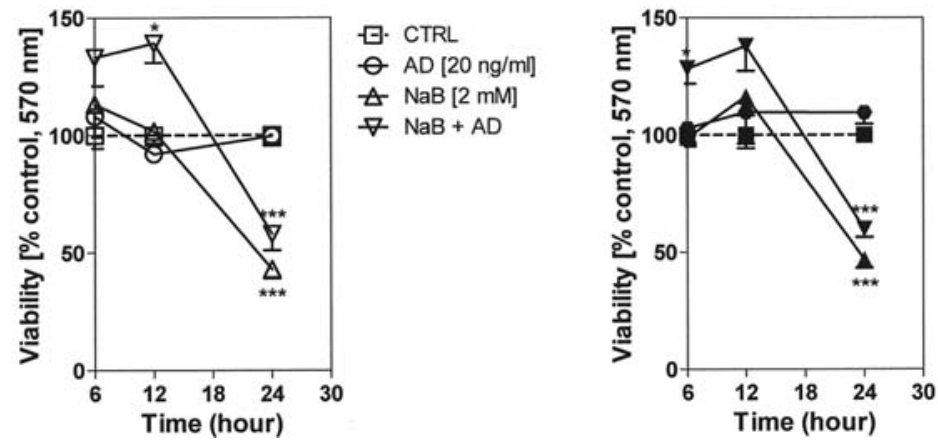

들 $\mathrm{MBCD}[2 \mathrm{mM}] / \mathrm{CTRL}$

- MBCD/AD [20 ng/ml]

$\pm \mathrm{M} \beta \mathrm{CD} / \mathrm{NaB}[2 \mathrm{mM}]$

$\rightarrow \mathrm{M} B \mathrm{CD} / \mathrm{NaB}+\mathrm{AD}$

Figure 4. Protein synthesis inhibitor CHX $(5 \mu \mathrm{g} / \mathrm{ml})$ and transcriptional inhibitor AD $(20 \mathrm{ng} / \mathrm{ml})$ prevent cell death promoting activity of NaB. Preincubation $(1 \mathrm{~h})$ with $\mathrm{MBCD}$ does not affect the $\mathrm{CHX}$ - and $\mathrm{AD}$-induced effects. ${ }^{* *} \mathrm{P}<0.01 ;{ }^{* *} \mathrm{P}<0.001$ values are statistically different from the control group $(\mathrm{P}<0.05)$.

diminished in both $\mathrm{S}$ and $\mathrm{R}$ fractions after $1 \mathrm{~h}$ of treatment with $2 \mathrm{mM}$ MßCD (Fig. 5B). Stock up of the plasma membrane with either of the cholesterol conjugate CHOL-PEG at concentration of $100 \mu \mathrm{g} / \mathrm{ml}$ (or CHOL-MBCD, not shown) restored $\mathrm{P}($ Ser473)-PKB/Akt1/2 to control level (Fig. 1B). This experiment clearly revealed how certain membrane fractions (non-raft vs. raft) could be transformed by the selected LR modulators in order to control the expression levels of particular LR anchored signaling proteins.

The expression levels of pro- and anti-apoptotic proteins are altered by $T N F-\alpha, N a B$ and imipramine. To find out how the translation inhibitor $\mathrm{CHX}$ protected COLO 205 cells against the NaB-induced cell death we determined the expression levels of regulatory proteins involved in apoptosis. We observed marked changes in the expression of anti-apoptotic (Bcl-2, cIAP-1, survivin, XIAP) vs. pro-apoptotic proteins (Bax, Bid) by $24 \mathrm{~h}$ of treatment with $\mathrm{NaB}$ and $\mathrm{TNF}-\alpha$ or $\mathrm{NaB}$ alone (Fig. 5C). AD (20 ng/ml) prevented viability of COLO 205 cells merely up to $12 \mathrm{~h}$, while non-specific translation inhibitor $\mathrm{CHX}$ protected cells from $\mathrm{NaB}$ toxicity during $24 \mathrm{~h}$ of treatment. At this time we found enhanced cytotoxicity exerted by $\mathrm{TNF}-\alpha$ and $\mathrm{NaB}$ was accompanied by elevated levels of TRADD adaptor protein and were paralleled by marked decline of XIAP and Bcl-2 proteins. IMP given individually stimulated XIAP and Bax expression, even though the latter protein expression increased considerably after TNF- $\alpha$ and $\mathrm{NaB}$ administration (Fig. 5C). On the contrary, the expression of anti-apoptotic proteins Bcl-2, survivin and XIAP declined each time $\mathrm{NaB}$ was added. In the latter case IMP slightly prevented the expression of survivin (Fig. 5C). Importantly, marked reduction in Bid expression was observed after combined treatment of $\mathrm{NaB}$ with TNF- $\alpha$ giving a clue for understanding how they could act synergistically in apoptosis induction.

Post-embedding immunocytochemistry, scanning and transmission electron microscopy. This approach was used to demonstrate, that LR modulator-dependent ultrastructural modifications could be observed at subcellular level and that they are in causal relationship with the cell injury. The cells treated for $1 \mathrm{~h}$ with MBCD or NY (2 mM, or $100 \mu \mathrm{g} / \mathrm{ml}$, respectively) showed loss of intracellular integrity (organelle swelling), reduced number of cilia and microvilli. After subsequent washing or cholesterol repletion the cells returned to normal appearance (Fig. 1A). Immunoreactivity of survival proteins points to the essential role of LR since they disappeared upon treatment with LR modulators, and 


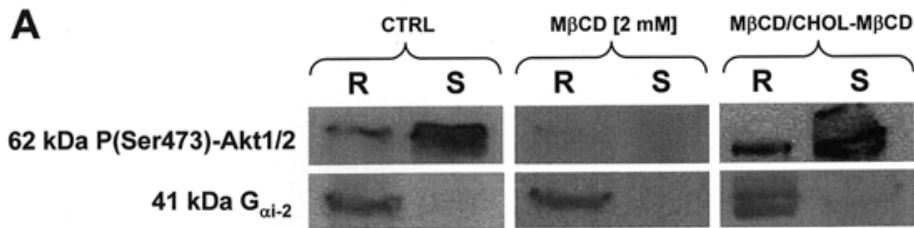

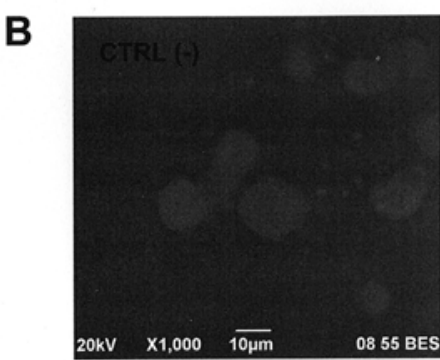
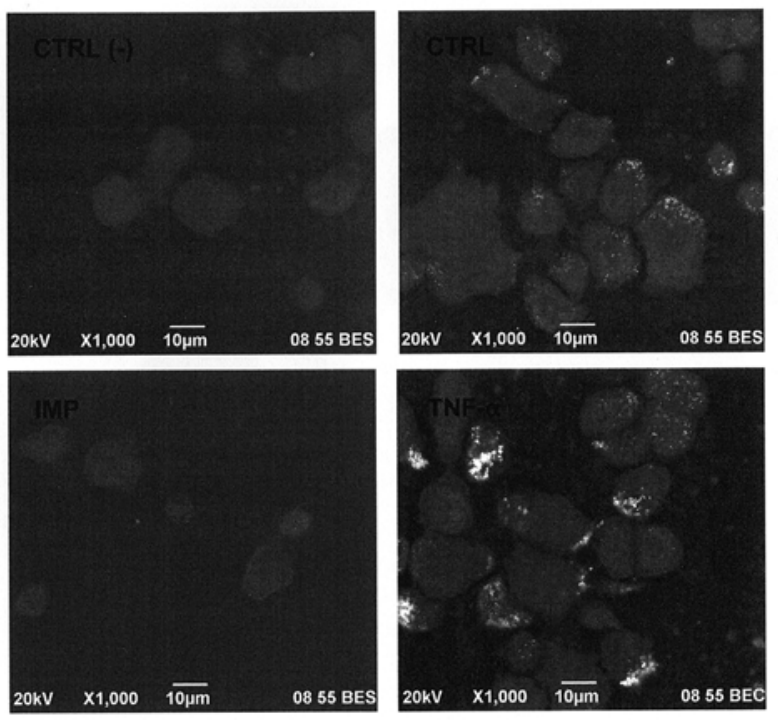

C

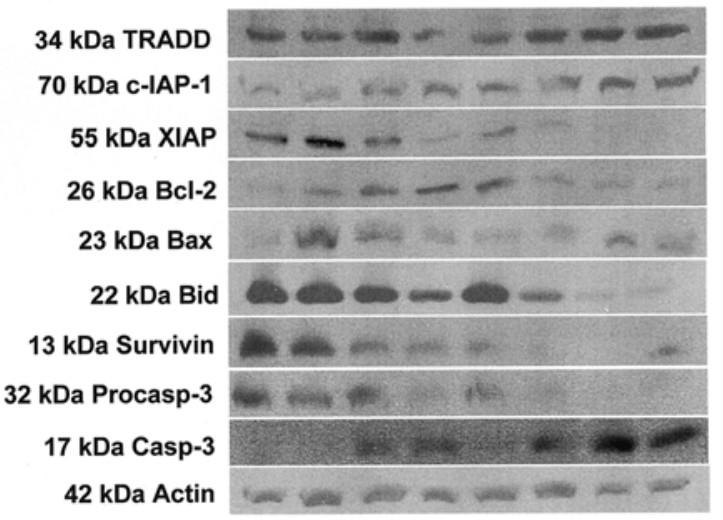

Figure 5. (A) Proteins in detergent soluble (S) and detergent resistant (R) membrane fractions were separated by SDS-PAGE and immunblotted with anti-G ${ }_{a i-2}$ and anti-P(Ser473)-PKB/Akt1/2 antiserum (see Material and methods). Pretreatment with MßCD (1 h) caused absolute loss of P(Ser473)-PKB/Akt1/2 expression levels in both fractions. Subsequent stock up of cholesterol (1 h with CHOL-MBCD, $100 \mu 1 / 15 \mathrm{ml})$ led to restitution of P(Ser473)-PKB/Akt1/2 expression in both S and R membrane fractions. (B) Scanning electron microscopy of COLO 205 cells cultured in Quantomix QX-102 capsules. After the experiment, cells were fixed as described by the manufacturer. TNF-R1 receptors were detected with monoclonal Ab and visualized with gold nanoparticles (18-nm diameter) conjugated to second donkey anti-mouse Ab. Clusters of TNF-R1 are clearly visible. Short-term (5 min) of TNF- $\alpha$ treatment led to noticeable increase in the size and intensity of spots representing colloidal gold particles. IMP efficiently blocks the surface expression of TNF-R1. CTRL (-) is a negative control where solely second Ab were used. (C) Immunoblots from whole-cell lysates showing the expression levels of TRADD, cIAP-1, XIAP, Bcl-2, Bax, Bid, procaspase-3 and caspase-3. Equal protein loading was confirmed by verification of actin level.

reappeared after subsequent treatment with cholesterol conjugates. Localization of selected lipid raft proteins and constituents was demonstrated with immunogold particles conjugated to secondary $\mathrm{IgG}$ raised against species specific primary antibody. A two-step procedure was used to show the presence of ceramides, $\mathrm{G}_{\alpha \mathrm{i}-2}$ heterotrimeric protein, and TNF-R1 in different cellular compartments including plasma membrane (Fig. 1A). To show occurrence of TNF-R1 on the surface of COLO 205 cells they were also cultured in QuantomiX QX-102 capsules. Appropriate experiments were conducted, and cells were processed according to the manufacturer's manual and visualized. The photographs revealed uneven and patchy distribution of spots representing TNF-R1 (Fig. 5B). The spots were of several magnitudes larger than individual gold particles conjugated with secondary antibodies $(18 \mathrm{~nm})$.

\section{Discussion}

Neoplastic diseases are often caused by the proteins aberrantly expressed at plasma membrane (reviewed in ref. 18). Human colon adenocarcinoma COLO 205 cells are typical for malignancies which are incurable with current therapeutic approaches due to a high anti-cancer drug resistance, even though these cells are Pgp-negative (19). Thus, plasma membrane proteins involved in the anomalous cell viability and mitogenicity should be suitable goals in targeted therapy $(20,21)$. In this study, we showed that approach, other than the typical anti-cancer drug treatment, is very promising.

Temporary removal of cholesterol from the plasma membrane (lipid rafts) inhibited activation of $\mathrm{PKB} / \mathrm{Akt} 1 / 2$ (Ser473 phosphorylation) and was further substantiated by the lack of Ser9 phosphorylation of GSK-3B (Fig. 5A). The latter kinase is a cognate substrate of $\mathrm{PKB} / \mathrm{Akt} 1 / 2$, that upon $\mathrm{PKB} / \mathrm{Akt} 1 / 2$-mediated Ser9 phosphorylation is unable to suppress cell survival (22). Inactivation of $\mathrm{PKB} / \mathrm{Akt} 1 / 2$ (Fig. 1B) evoked reduction in cell viability (Fig. 2A, $\mathrm{P}<0.001)$, but this effect was reversed through the revitalization of cells with cholesterol replenishment as shown by ultrastructural examination (Fig. 1A). Neoplastic cells are principally affected by modulation of LR $(23,24)$ since it has been known for a century that they hold elevated levels of cholesterol (25). The analysis showed reversible fluctuations of PKB/Akt1/2 Ser473 phosphorylation which were brought about in concert with chelation and subsequent repletion of plasma membrane cholesterol (Fig. 1B). CHOLrich lipid rafts are essential for PKB/Akt1/2 kinase activation (26) and tumor cells are particularly sensitive to apoptosis upon CHOL depletion (24). Our observations are consistent with studies showing that LR are essential for maintaining 
the activity of PI3-K/PKB/Akt1/2 signaling pathway $(1,26)$ but they also indicate the importance of survival systems other than the LR-dependent one. Cho et al (27) showed in elegant study that when mice were given simvastatin, an inhibitor of HMG-CoA reductase (step-limiting enzyme in cholesterol synthesis), the decline in viability was followed by necrosis of xenografted COLO 205 cells.

COLO 205 cells are immune to extrinsic apoptosis induced by death ligands, although they express surface death receptors (TNF-R1, TNF-R2, TRAIL-R1, TRAIL-R2, Fas) as demonstrated by FACS (28) or by immunoprecipitation (29). The immune escape of COLO 205 cells from TNF- $\alpha-$ mediated apoptosis is in part the outcome of extensive shedding of TNF-R1 and TNF-R2 (30) and/or by cFLIP protein inhibitory effect on caspase- 8 activation (31). The latter case was confirmed by sensitization of COLO 205 cells upon treatment with $\mathrm{CHX}$, a non-specific protein synthesis inhibitor. Similarly, unresponsiveness of COLO 205 cells to TNF- $\alpha$ has been overcome by bisindolylmaleimide IX (32) or by $\mathrm{NaB}$ (17). $\mathrm{NaB}$ is of special interest, since this is a natural product of fiber fermentation in the gut, and it is a powerful apoptosis inducing agent (33). As we previously reported, NaB-mediated effect facilitated the TNF- $\alpha$ activity, although temporary $\mathrm{CHOL}$ depletion with $\mathrm{MBCD}$ did not limit this reaction (Fig. 3B, $\mathrm{P}>0.05$ ). The decline in $\mathrm{Bid}$ expression by $24 \mathrm{~h}$ of $\mathrm{NaB}$ and $\mathrm{TNF}-\alpha$ combined treatment suggests, that death promoting signal from TNF-R1 was amplified by $\mathrm{NaB}$ through the activation of Bid (tBid), and that $1 \mathrm{~h} \mathrm{MBCD}$ pretreatment was unable to impede $\mathrm{NaB}$-aided signal transduction from TNF-R1.

Growing body of evidence suggest that cholesterol plays a dual role in cell signaling. This sterol compound of LR is important both for survival and death signals $(34,35)$. Depending on time and concentration the depletion of CHOL with MBCD or NY led to drop in metabolic activity of COLO 205 cells and finally to cell deletion (Fig. 2A, $\mathrm{P}<0.001$ ), or occurrence of morphological changes (loss of microvilli, swollen mitochondria, degranulation of RER) which were reversed when CHOL was refilled (Fig. 1A). Interestingly, modifications of raft composition might change the upshot originated in LR. Both SPHING and CHOL seem to be indispensable for the maintenance of LR functionality and cell viability (1). Moreover, LR embedded in receptosomes and endosomes allow continuous intracellular signaling unless the signalosomes remain intact (36). Small diameter of LR (5-20 nm) make these entities unlikely to contain enough receptor proteins to elicit any signal.

It is generally believed that LR might cluster into larger platforms (37). We provide evidence (Fig. 5B) that TNF-R1 surface receptors form clusters if one admits that spots observed from TNF-R1 immunocytochemical study are several hundred nanometers in diameter. They were localized to the surface of leading edge in COLO 205 cells (Fig. 5B) suggesting that this is a chemoreceptive zone. If LR form a link between extrinsic and intrinsic apoptotic pathway, then it explains how TNF- $\alpha$ and $\mathrm{NaB}$ can act in accordance. There is room for sphingomyelinases, which by release of ceramides permit the formation of gangliosides (glycosphingolipids) known to activate intrinsic apoptosis (5). When IMP was added, cell viability increased (Fig. 2B, P<0.001), and $\mathrm{NaB}$ cytotoxicity was reduced (Fig. 2B). Noteworthy, there was no effect of IMP on NaB-dependent potentiation of TNF- $\alpha$ cell death promoting activity (Fig. $2 \mathrm{~B}, \mathrm{P}>0.05$ ). The latter finding might be explained by the ceramide-independent apoptotic pathway triggered by combined treatment of TNF- $\alpha$ and $\mathrm{NaB}$. This was not checked by, but some authors suggest the prominent role of neutral sphingomyelinase (nSMAse) in cell death evoked in tumor cells (38). nSMAse is not targeted by IMP but is activated by PUFA, and PUFA are known to make LR poorer in CHOL and SPHING but richer in phosphatidylcholine (39). Thus, PUFA and $\mathrm{NaB}$ may act differently (40) pointing to less clear outcome of IMP use. This was more evident in the measurement of mitogenicity, where DNA synthesis was lesser in IMP treatment in common with $\mathrm{NaB}$ and TNF- $\alpha$ (Fig. 3C). Perhaps the number of surface receptors is an important causal factor, since in the IMP treated COLO 205 cells no TNF-R1 receptors were detected (Fig. 5B).

EGCG-dependent stimulation of COLO 205 cell viability was reversed by co-treatment with TNF- $\alpha$, similarly to LR modulators (Fig. 3B, $\mathrm{P}<0.05$ ). We concluded that EGCG effect is mediated by LR, and that TNF- $\alpha$ could be holding up EGCG activity, though this cytokine given alone stimulated cell survival (Fig. $2 \mathrm{~B}, \mathrm{P}<0.01$ ). Administration of IMP, the aSMAse inhibitor revealed that even then, viability of COLO 205 cells was to some extent hampered by unknown factors (Fig. 2B, $\mathrm{P}<0.01$ ). The TNF- $\alpha$-induced effect was LR-dependent as MßCD co-treatment lessen the NaB-dependent aid to TNF- $\alpha$ cytotoxicity (Fig. 3B, $\mathrm{P}<0.01$ ).

The use of volatile fatty acids such as butyrate (sodium salt) is a powerful instrument in the eradication of colon tumors (41). In our study, this low-molecular weight substance (depending on concentration, 2-5 $\mathrm{mM}$ ) was able to eliminate $60-80 \%$ of tumor cells (Figs. $2 \mathrm{~B}$ and $3 \mathrm{~B}, \mathrm{P}<0.01$ ). Furthermore, TNF- $\alpha$, previously shown to be negligible in cell deletion appeared cytotoxic in the presence of $\mathrm{NaB}$ (Figs. 2B and 3B, $\mathrm{P}<0.05$ ). Earlier we reported that in contrast to NaB, CHX sensitized COLO 205 cells to TNF- $\alpha$ dependent extrinsic apoptosis, where resistance relied upon anti-apoptotic FLIP protein (31). The finding that CHX blocked cytotoxicity of $\mathrm{NaB}$ points to de novo synthesis of proapoptotic proteins, degradation of anti-apoptotic proteins or both as crucial factors in the death promoting effect of $\mathrm{NaB}$. None of the NaB-induced effects was dependent on LR, because neither MBCD nor NY, could reverse NaB cytotoxicity. Similarly, IMP, an inhibitor of aSMAse, could not inhibit NaB-induced cytotoxicity of $\mathrm{TNF}-\alpha$, although it markedly reduced the effect of $\mathrm{NaB}$ or TNF- $\alpha$ given alone (Fig. 2B, P<0.05). It indicates, that IMP and lack of ceramides significantly stimulated viability of COLO 205 cells. Actually, IMP stimulated cell viability in parallel to a marked reduction in the expression of TNF-R1 (Fig. 5B).

To our knowledge, this study gives the first evidence that TNF-R1 receptors are clustered in COLO 205 cells without addition of the cognate ligand. We also provide compelling evidence that acid sphingomyelinase (aSMAse) inhibitor imipramine (IMP) blocks the appearance of TNFR1. Additionally, the study indicates that sodium butyrate (NaB) toxicity against COLO 205 cells acts independently of the lipid rafts, but its action is inhibited by non-specific 
translation and transcription inhibitors. These results indicate, that de novo protein synthesis, rather than posttranscriptional modifications play important role in $\mathrm{NaB}$ enhanced cell death. In fact, $\mathrm{NaB}$ is known as a histone deacetylase inhibitor, which by epigenetic correction of gene activity triggers differentiation and/or apoptosis of gut epithelia $(42,43)$. Immunoblotted proteins separated by SDSPAGE confirmed that $\mathrm{NaB}$ with the exception of cIAP-1 elevated pro- (Bax, caspase-3) and lowered the expression of antiapoptotic proteins (Bcl-2, XIAP, survivin, Fig. 5C). Furthermore, procaspase- 3 has been converted to caspase- 3 whenever $\mathrm{NaB}$ was given alone or together with TNF- $\alpha$ (Fig. 5C). Bid expression was decreased at this same time. This study confirms our recent study (17) that $\mathrm{NaB}$ induces intrinsic apoptosis and facilitates TNF- $\alpha$-dependent extrinsic apoptosis. Metabolic activity of COLO 205 cells descended in concert with the reduced level of procaspase- 3 and was counterbalanced by increased levels of caspase-3 (Fig. 5C). Moreover, the expression of TRADD adaptor protein was elevated if $\mathrm{NaB}$ and $\mathrm{TNF}-\alpha$ were used together. This result indicate that $\mathrm{NaB}$ administration might be considered as an important determinant of the TRADD protein expression. The latter is essential for the assembly of signalosome at TNF-R1. It was actually $\mathrm{NaB}$ that sensitized COLO 205 adenocarcinoma cells to TNF- $\alpha$ rather than vice versa.

Selected anti-cancer drugs (CIS and CLA) applied in moderate concentrations apparently did not diminish viability of COLO 205 cells (Fig. 2C, P>0.05), whereas high, toxic concentrations were successful merely by $24 \mathrm{~h}$ of treatment (data not shown). These results might raise a question whether these cytostatics are of any use in the elimination of colorectal cancers. However, Gong et al (28) showed that e.g. paclitaxel (taxan) used sequentially with TRAIL could efficiently induce cell death in xenografts and cultured COLO 205 cells. Paclitaxel elevated the expression of TRAIL surface receptors by post-translational mechanism that could not be circumvented either by protein synthesis or transcription inhibitors (28). To verify whether the tested compounds can sensitize colorectal cancers to death ligand cytotoxicity, additional studies are required.

\section{Acknowledgements}

We thank Ryszard Strzalkowski for his excellent technical assistance in transmission and scanning electron microscopy. We are also grateful to Elzbieta Kania for her help in SDSPAGE and immunoblotting. This work was supported by the Polish Ministry of Science and Higher Education, Grant No. NN 404152 434. In 2010 B.P. was granted by L'OrealUNESCO foundation 'For Women in Science' and received a fellowship from the Ministry of Science and Higher Education 'For Young Outstanding Scientists' in Poland.

\section{References}

1. Lasserre R, Guo X-J, Conchonaud F, Hamon Y, Hawchar O, Bernard A-M, Soudja SM, Lenne P-F, Rignault H, Olive D, Bismuth G, Nunes JA, Payrastre B, Marguet D and He H-T: Raft nanodomains contribute to Akt/PKB plasma membrane recruitment and activation. Nat Chem Biol 4: 538-547, 2008

2. Hancock JF: Lipid rafts: contetious only from simplistic standpoints. Nat Rev Mol Cell Biol 7: 456-462, 2006.
3. Radhakrishan A and McConnell HM: Condensed complexes of cholesterol and phospholipids. Biophys J 77: 1507-1517, 1999.

4. Simons K and Toomre D: Lipid rafts and signal transduction. Nature Rev 1: 31-41, 2000.

5. Colell A, Morales A, Fernandez-Checa JC and Garcia-Ruiz C: Ceramide generated by acidic sphingomyelinase contributes to tumor necrosis factor- $\alpha$-mediated apoptosis in human colon HT-29 cells thorugh glycosphingolipids formation. FEBS Lett 526: 135-141, 2002.

6. Simons K and van Meer G: Lipid sorting in epithelial cells. Biochemistry 27: 6197-6202, 1998

7. Patra SK: Dissecting lipid rafts facilitated cell signaling pathways in cancer. Biochim Biophys Acta 2: 182-206, 2008.

8. Golub T, Wacha S and Caroni P: Spatial and temporal contraol of signaling through lipid rafts. Curr Opinion Neurobiol 14: 542-550, 2004

9. Gajate C and Mollinedo F: Cytoskeleton-mediated death receptor and ligand concentration in lipid rafts forms apoptosis-promoting clusters in cancer chemotherapy. J Biol Chem 280: 11641-11647, 2005.

10. Klein U, Gimple G and Fahrenholz F: Alteration of the myometrial plasma membrane cholesterol content with B-cyclodextrin modulates the binding affinity of the oxytocin receptor. Biochemistry 34: 13784-13793, 1995.

11. Gimple G, Klein U, Reilander H and Fahrenholz F: Expression of the human oxytocin receptor in Baculovirus-infected insect cells: high-affinity binding in induced by cholesterol-cyclodextrin complex. Biochemistry 34: 13794-13801, 1995.

12. Jacobson MD, Burne JF and Raff MC: Programmed cell death and $\mathrm{Bcl}-2$ protection in the absence of a nucleus. EMBO J 13: 1899-1910, 1994

13. Drevot P, Langlet C, Guo X-J, Langlet A-M, Colard O, Chauvin J-P, Lasserre R and He H-T: TCR signal initiation machinery is pre-assembled and activated in a subset of membrane rafts. EMBO J 21: 1899-1908, 2002.

14. Remacle-Bonnet M, Garrouste F, Baillat G, Andre F, Marvaldi J and Pommier G: Membrane rafts segregate pro- and antiapoptotic insulin-like growth factor-I receptor signaling in colon carcinoma cells stimulated by members of the tumor necrosis factor superfamily. Am J Pathol 167: 761-773, 2005.

15. Bradford MM: A rapid and sensitive method for the quantitation of microgram quantities of protein utilizing the principle of protein-dye binding. Anal Biochem 72: 248-254, 1976.

16. Lacour S, Haummann A, Grazide S, Lagadic-Gossmann D, Athias A, Sergent O, Laurent G, Gambert P, Solary E and Dimanche-Boitrel M-T: Cisplatin-induced CD95 redistribution into membrane lipid rafts of HT29 human colon cancer cells. Cancer Res 64: 3593-3598, 2004.

17. Pajak B, Gajkowska B and Orzechowski A: Sodium butyrate sensitizes human colon adenocarcioma COLO 205 cell to both intrinsic and TNF- $\alpha$-dependent extrinsic apoptosis. Apoptosis 14: 203-217, 2009.

18. Croce CM: Oncogenes and cancer. N Engl J Med 358: 502-511, 2008.

19. Jansen WJM, Pinedo HM, van der Wilt CL, Feller N, Bamberger U and Boven E: The influence of BIBW22BS, a dipyridamole derivative, on the antiproliferative effects of 5-fluorouracil, methotrexate and gemcitabine in vitro and in human tumour xenografts. Eur J Cancer 31: 2313-2319, 1995.

20. Pawlak WZ: The myb genes as a target for anticancer therapy. Contemp Oncol 6: 216-221, 2002.

21. Firestein R, Bass AJ, Kim SY, Dunn IF, Silver SJ, Guney I, Freed E, Ligon AH, Vena N, Ogino S, Chheda MG, Tamayo P, Finn S, Shrestha Y, Boehm JS, Jain S, Bojarski E, Mermel C, Barretina J, Chan JA, Baselga J, Tabernero J, Root DE, Fuchs CS, Loda M, Shivdasani RA, Meyerson M and Hahn WC: CDK8 is a colorectal cancer oncogene that regulates beta-catenin activity. Nature 455: 479-480, 2008.

22. Caspi M, Zilberberg A, Eldar-Finkelman H and RosinArbersfeld R: Nuclear GSK-3beta inhibits the canonical Wnt signalling pathway in a beta-catenin phosphorylation-independent manner. Oncogene 27: 3546-3555, 2008.

23. Li HY, Appelbaum FR, Willman CL, Zager RA and Banker DE: Cholesterol-modulating agents kill acute myeloid leukemia cells and sensitize them to therapeutics by blocking adaptive cholesterol responses. Blood 101: 3628-3634, 2003.

24. Li YC, Jung MJ, Ye S-K, Kim C-W and Kim Y-N: Elevated levels of cholesterol-rich lipid rafts in cancer cells are correlated with apoptosis sensitivity induced by cholesterol-depleting agents. Am J Pathol 168: 1107-1118, 2006. 
25. White RM: On the ocurrence of crystals in tumors. J Pathol Bacteriol 13: 3-10, 1909.

26. Zhuang L, Lin J, Lu ML, Solomon KR and Freeman MR: Cholesterol-rich lipid rafts mediate Akt-regulated survival in prostate cancer cells. Cancer Res 62: 2227-2231, 2002.

27. Cho S-J, Kim JS, Kim JM, Lee JY, Jung HC and Song IS Simvastatin induces apoptosis in human colon cancer cells and in tumor xenografts, and attenuates colitis-associated colon cancer in mice. Int J Cancer 123: 951-957, 2008.

28. Gong J, Yang D, Kohanim S, Humphreys R, Broemling L and Kurzrock R: Novel in vivo imaging shows up-regulation of death receptors by paclitaxel and correlates with enhanced antitumor effects of receptor agonist antibodies. Mol Cancer Ther 5: 2991-3000, 2006

29. Pajak B, Gajkowska B and Orzechowski A: Position of STAT$1 \alpha$ in cycloheximide-dependent apoptosis triggered by TNF- $\alpha$ in human colorectal COLO 205 cancer cell line; role of polyphenolic compounds. J Physiol Pharmacol 56 (Supp1 3): 119-141, 2005.

30. Lombard MA, Wallace TL, Kubicek MF, Petzold GL, Mitchell MA, Hendges SK and Wilks JW: Synthetic matrix metalloproteinase inhibitors and tissue inhibitor of metalloproteinase (TIMP)-2, but not TIMP-1, inhibit shedding of tumor necrosis factor- $\alpha$ receptors in a human colon adenocarcinoma (Colo 205) cell line. Cancer Res 58: 4001-4007, 1998.

31. Pajak B, Gajkowska B and Orzechowski A: Cycloheximidemediated sensitization to TNF- $\alpha$-induced apoptosis in human colorectal cancer cell line Colo 205; role of FLIP and metabolic inhibitors. J Physiol Pharmacol 56 (Supp1 3): 101-118, 2005.

32. Pajak B, Turowska A, Orzechowski A and Gajkowska B Bisindolylmaleimide IX facilitates extrinsic and initiates intrinsic apoptosis in TNF- $\alpha$-resistant human colon adenocarcinoma COLO 205 cells. Apoptosis 13: 509-522, 2008.

33. Hernandez A, Thomas R, Smith F, Sandberg J, Kim S, Chung DH and Evers BM: Butyrate sensitizes human colon cancer cells to TRAIL-mediated apoptosis. Surgery 130: 265-272, 2001.

34. Schutze S and Schneider-Brachert W: Impact of TNF-R1 and CD95 internalization on apoptotic and antiapoptotic signaling. Results Probl Cell Differ 49: 63-85, 2009.
35. Oh HY, Lee EJ, Yoon S, Chung BH, Cho KS and Hong SJ: Cholesterol level of lipid raft microdomains regulates apoptotic cell death in prostate cancer cells through EGFR-mediated Akt and ERK signal transduction. Prostate 67: 1061-1069, 2007.

36. Schneider-Brachert W, Tchikov V, Neumeyer J, Jakob M, Winoto-Morbach S, Held-Feindt J, Heinrich M, Merkel O, Ehrenschwender M, Adam D, Mentlein R, Kabelitz D and Schutze S: Compartmentalization of TNF Receptor 1 signaling: internalized TNF receptosomes as death signaling vesicles. Immunity 21: 415-428, 2004.

37. Veatch SL: From small fluctuations to large-scale phase separation: Lateral organization in model membranes containing cholesterol. Semin Cell Dev Biol 18: 573-582, 2007.

38. Wu M, Harvey KA, Ruzmetov N, Welch ZR, Sech L, Jackson K, Stillwell W, Zaloga GP and Siddiqui RA: Omega-3 polyunsaturated fatty acids attenuate breast cancer growth through activation of a neutral sphingomylinase-mediated pathway. Int J Cancer 117: 340-348, 2005.

39. Fan YY, McMurray DN, Ly LH and Chapkin RS: Dietary n-3 polyunsaturated faty acids remodel mouse T-cell lipid rafts. J Nutr 133: 1913-1920, 2003.

40. Hofmanova J, Vaculova A, Koubkova Z, Hyzdalova M and Kozubik A: Human fetal colon cells and colon cancer cells respond differently to butyrate and PUFAs. Mol Nutr Food Res 53: S102-S113, 2009.

41. Litvak DA, Hwang KO, Evers BM and Townsend CM: Induction of apoptosis in human gastric cancer by sodium butyrate. Anticancer Res 20: 779-784, 2000.

42. Sealy L and Chalkley R: The effect of sodium butyrate on histone modification. Cell 14: 115-121, 1978.

43. Heerdt BG, Houston MA and Augenlicht LH: Short-chain fatty acid-initiated cell cycle arrest and apoptosis of colonic epithelial cells is linked to mitochondrial functions. Cell Growth Differ 8: 523-532, 1997. 